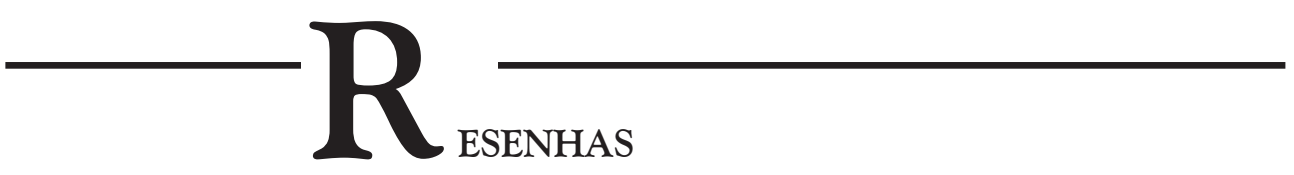

ROMBERG, Raquel. Witchcraft and welfare: spiritual capital and the business of magic in modern Puerto Rico. Austin: Texas University Press, 2003, 315 pp.

\title{
LA MERCANTILIZACIÓN DE LA FE Y EL PROCESSO DE RESIGNIFICACIÓN DE LAS PRÁCTICAS DE BRUjería Y SANACión EN PUERTO Rico
}

\section{Analía Kerman}

Combinando la perspectiva histórico-etnográfica, la antropóloga Raquel Romberg introduce al lector en el universo de las prácticas de brujería y sanación en Puerto Rico inscriptas en el actual contexto de globalización y capitalismo flexible. En su original propuesta, se explora en profundidad la emergencia histórica de las prácticas espirituales vernáculas portorriqueñas originadas en la combinación de doctrinas cristianas, religiones afrocubanas y prácticas propias del espiritismo francés de comienzos del siglo XX. En este sentido, la categoría nativa de "brujería" es retomada por la autora para referirse al complejo de prácticas religiosas populares heterodoxas donde la magia, los rituales y las prácticas de sanación son ejecutados por agentes específicos (brujos), cuyos dones y conocimientos los posiciona como mediadores entre los planos espiritual y terrenal, habilitando su actuación concreta en el devenir de la vida de las personas.

Romberg argumenta que la brujería ha sabido adaptarse a los cambios políticos 
y económicos del último siglo ganando protagonismo en la escena local. Así, lejos de tratarse de una práctica marginal o exótica, se ha convertido en un socio invisible y activo del capitalismo a través del proceso de mercantilización de la fe o conmodification.

A través de la indagación en el complejo entramado geopolítico y las resignificaciones de esta forma de espiritualidad, la autora nos brinda interesantes aportes relativos al abordaje de la cuestión socioreligiosa en América Latina.

Romberg organiza el relato en dos partes. En la primera, explora la matriz histórica de la brujería portorriqueña contextualizando su emergencia en función de los discursos nacionales, políticos, económicos y religiosos de la isla. Para ello, distingue tres momentos en el proceso de globalización iniciado en 1502, cuando la esclavitud y la hegemonía del catolicismo español eran los elementos claves. A mediados del siglo XIX, con la emergencia de las luchas independentistas y el crecimiento del sentimiento anti-hispánico, se desarrolla un segundo período caracterizado por el influjo de las creencias protestantes y las influencias religiosas del espiritualismo kardecista. El examen de estas últimas en relación a los desarrollos de la brujería es una contribución adeudada a los estudios de religión en el Caribe. Igualmente admirable es el tratamiento que realiza de la tercera oleada de intensificación de la globalización en la isla, desde 1980 hasta el presente, a la que denomina commodification, en oposición al paradigma de secularización que aboga por la remisión del misticismo en contextos altamente industrializados. La autora demuestra que la brujería se desarrolla en espacios multiculturales, propiciada por el laissez-faire heretodoxo espiritual y en respuesta a un creciente mercado cada vez más competitivo. En los últimos veinte años se ha convertido en una fuerza local emergente que trabaja en conjunto con, más que en oposición a, los valores del consumidor capitalista y sus estándares de bienestar. Entendida como una forma de "materialismo espiritualizado", combina diversas formas de religiosidad afro-latina con el ethos del bienestar poscapitalista norteamericano y, aunque invisibilizada, no ocupa un lugar marginal ni se propone como una forma de resistencia a los procesos de modernización estatal. Por el contrario, contribuye a la reproducción del orden social no sólo a través de sus tipos de intervención holísticos e individualizados, sino también aprobando y promoviendo los valores sociales dominantes que redirigen el accionar de sus clientes. Lejos de ser especies peligrosas o potenciales fuerzas subversivas, los brujos responden a las necesidades emocionales, económicas y espirituales de sus consultantes, operando como mediadores entre el mundo terrenal y el mundo de los espíritus, y ocupando espacios sociales otrora regulados por el estado y los agentes comerciales.

En la segunda parte del libro, a partir de una detallada descripción etnográfica, Romberg argumenta que, de acuerdo con los actores, los bienes espirituales se acumulan e intercambian en el plano terrenal con miras a lograr tanto la prosperidad material como espiritual. 
Los brujos, lejos de ser especies en vías de extinción en los márgenes de la sociedad moderna, poseen la habilidad de administrar las adversidades sociales e intervenir en asuntos personales. En palabras de la autora, ellos operan en la interfaz entre la seguridad social y los servicios médicos y sociales maximizando, por lo tanto, las oportunidades de sus clientes en las áreas grises de la jurisdicción institucional. La mediación entre los espíritus y sus clientes es en sí misma el comienzo de un proceso reconstituyente de sanación.

Asimismo, expone que, lejos de circunscribirse a un grupo étnico en particular o de ser una práctica cerrada, la brujería es una forma abierta, en constante cambio y permeable a la innovación. En este sentido, la mercantilización de la brujería no es un proceso novedoso así como tampoco lo es el eclecticismo de sus rituales, pero lo que ha cambiado drásticamente en condiciones de alta modernidad, transnacionalización e intensificación de la globalización es la eficiencia y la rapidez con que las innovaciones rituales viajan y la disposición de los actores para aprobar y hasta promocionar algunos aspectos de la brujería, sobre todo sus componentes étnicos.

Los flujos globales de personas, bienes e ideas promueven la particularización e individualización de las prácticas espirituales más que su homogeneización. En estas nuevas condiciones, el aspecto empresarial de la brujería encuentra suelo fértil para un desarrollo ecléctico y prolífico, independientemente de las expectativas de aquellos que aún la conciben como un conjunto de prácticas meramente etnicizadas. Consecuentemente, los brujos han dejado de ser perseguidos y catalogados como charlatanes para pasar a reinventarse como empresarios espirituales y, de esta manera, redefinir las formas que toma la brujería portorriqueña en la actualidad.

\footnotetext{
Analía Kerman

(kerman@fibertel.com.ar/anabarbarella@hotmail.com)

Membro do Prometo de Pesquisa UBACYT F 150, "Modernidad, espíritu y poder. Etnografía de heterodoxias sociorreligiosas en la Argentina", dirigido pelo Dr. Pablo Wright no Instituto de Ciências Antropológicas, Seção de Etnología y Etnografía, Faculdade de Filosofía e Letras, Universidade de Buenos Aires.
} 